\title{
The Ac2-26 peptide of ANXA1 protects against sepsis-induced acute kidney injury by negatively regulating the PI3K/IKK/NF-xB pathway
}

\author{
yanlei zheng ${ }^{1}$, Li Zhu ${ }^{1}$, Ronghua $\mathrm{Hu}^{1}$, Fei Cheng ${ }^{1}$, Chenchen $\mathrm{Hu}^{1}$, and Li Zhang ${ }^{1}$ \\ ${ }^{1}$ Hubei Cancer Hospital
}

May 4, 2020

\begin{abstract}
BACKGROUD AND PURPOSE The aim of the present study was to explore the effects of annexin A1 (ANXA1) mimetic peptide $\mathrm{AC} 2-26$ on sepsis-induced acute kidney injury by negatively regulating the PI3K/IKK/NF- $\varkappa \mathrm{B}$ pathway in vivo and in vitro and the underlying mechanisms. EXPERIMENTAL APPROACH In vivo, a mouse model was established by cecal ligation and puncture (CLP), and the Ac2-26 peptide of ANXA1 $(1 \mathrm{mg} / \mathrm{kg})$ was intraperitoneally administered 2 hours before CLP. In vitro, A model of HK-2 cells was established by treatment with $10 \mu \mathrm{g} / \mathrm{ml}$ lipopolysaccharide (LPS), and the Ac2-26 peptide of ANXA1 $(0.5 \mu \mathrm{mol} / \mathrm{L})$ was administered 2 hours before LPS. The kidney function of mice detected by Elisa. The kidney tissue was examined by HE and TEM. The inflammatory cytokines and apoptotic molecules were measured by PCR, Elisa, Western blotting and Immunohistochemistry. The apoptosis was detected by TUNEL and flow cytometry. KEY RESULTS The studies demonstrated that ANXA1 markedly improved kidney function and kidney tissue injury and enhanced 7-day survival in CLP-induced septic mice, which was accompanied by a significant decrease the inflammatory molecules. ANXA1 obviously downregulated the apoptosis-associated proteins and inhibited apoptosis in kidney tissue in vivo. In vitro studies showed that ANXA1 increased the viability of HK-2 cells, reduced the levels of the inflammatory molecules, downregulated the apoptosis-associated proteins Bax, upregulated the antiapoptotic protein Bcl-2 and inhibited the apoptosis of HK-2 cells. CONCLUSION AND IMPLICATIONS These results demonstrate that ANXA1 is a potential chemotherapeutic agent against septic AKI through negative regulation of the PI3K/IKK/NF- $x \mathrm{~B}$ pathway.
\end{abstract}

\section{Hosted file}

The Ac2-26 peptide of ANXA1 protects against sepsis-induced acute kidney injury by negatively regulatin available at https://authorea.com/users/317473/articles/447557-the-ac2-26-peptide-of-anxa1protects-against-sepsis-induced-acute-kidney-injury-by-negatively-regulating-the-pi3k-ikk$\mathrm{nf}-\% \mathrm{CE} \% \mathrm{BAb}-$ pathway 


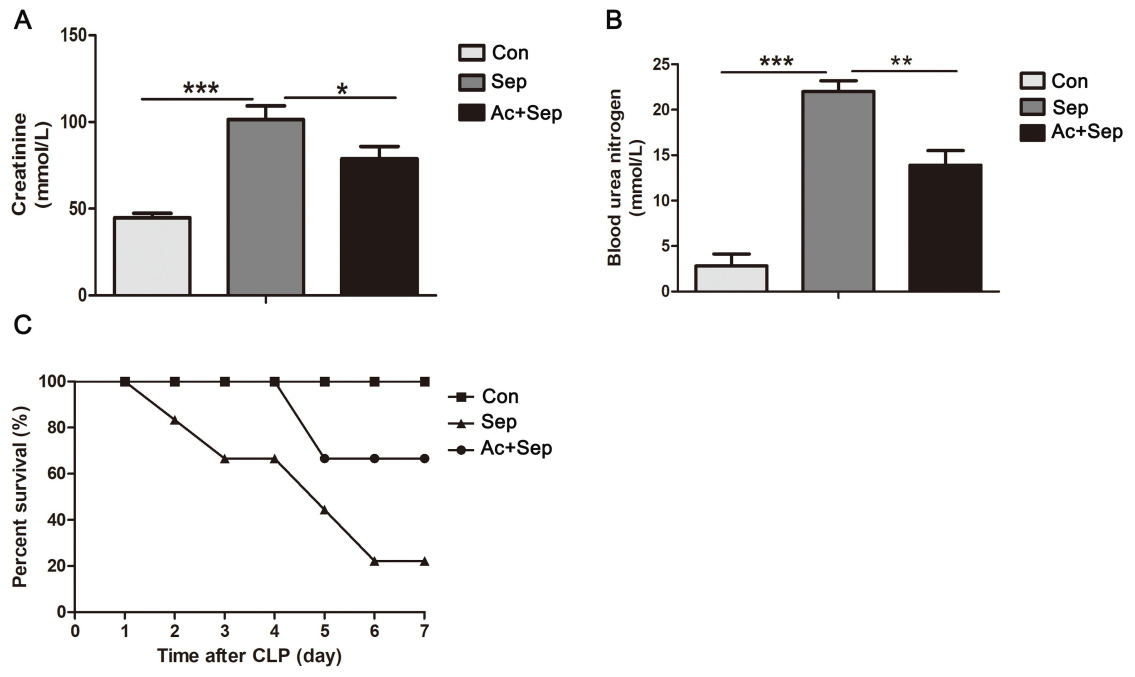




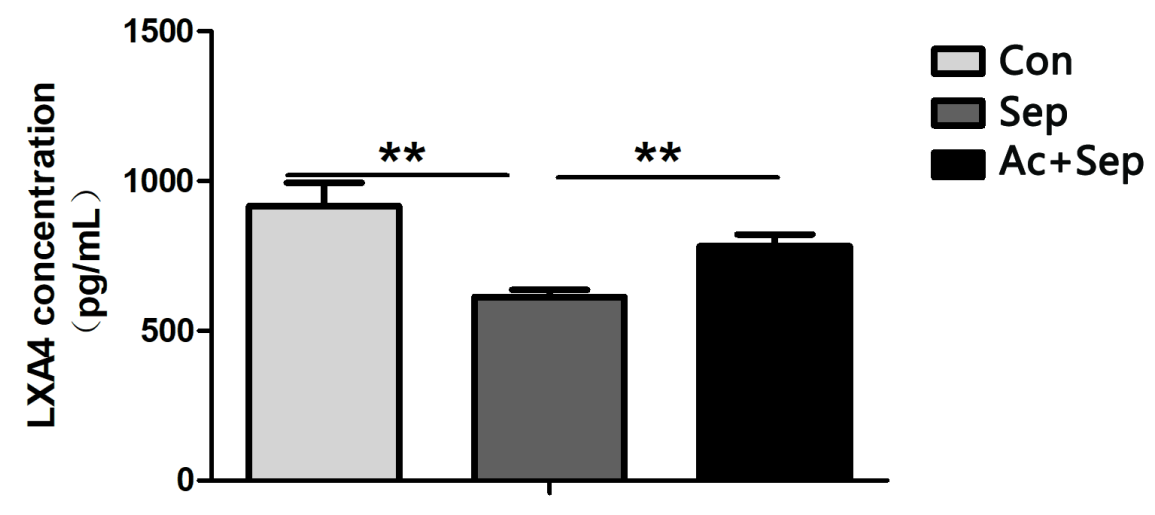

\section{Hosted file}

Figure 3.pdf available at https://authorea.com/users/317473/articles/447557-the-ac2-26-peptideof-anxa1-protects-against-sepsis-induced-acute-kidney-injury-by-negatively-regulating-thepi3k-ikk-nf-\%CE\%BAb-pathway

\section{Hosted file}

Figure 4.pdf available at https://authorea.com/users/317473/articles/447557-the-ac2-26-peptideof-anxa1-protects-against-sepsis-induced-acute-kidney-injury-by-negatively-regulating-thepi3k-ikk-nf-\%CE\%BAb-pathway

\section{Hosted file}

Figure 5.pdf available at https://authorea.com/users/317473/articles/447557-the-ac2-26-peptideof-anxa1-protects-against-sepsis-induced-acute-kidney-injury-by-negatively-regulating-thepi3k-ikk-nf-\%CE\%BAb-pathway 


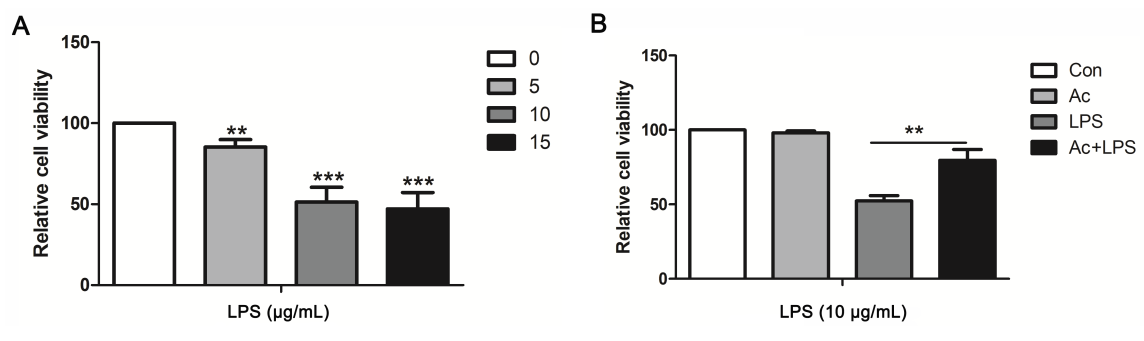




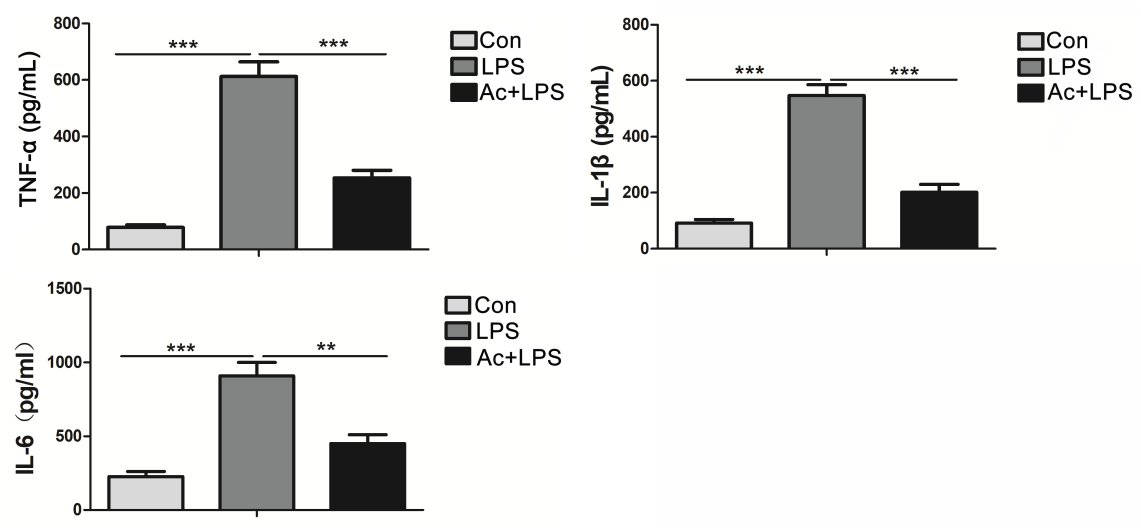

\section{Hosted file}

Figure 8.pdf available at https://authorea.com/users/317473/articles/447557-the-ac2-26-peptideof-anxa1-protects-against-sepsis-induced-acute-kidney-injury-by-negatively-regulating-thepi3k-ikk-nf-\%CE\%BAb-pathway 


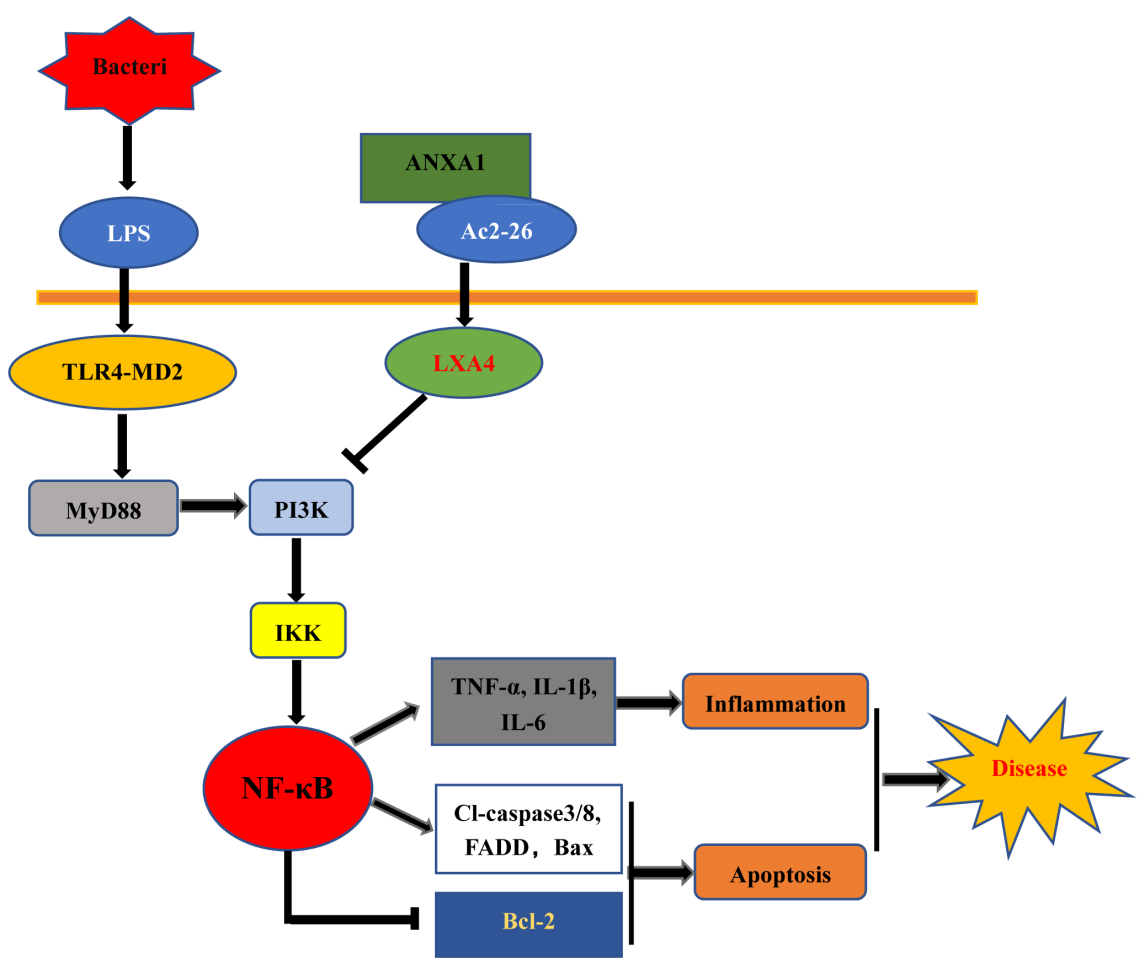


Table 1 Primer sequences for quantitative RT-PCR

\begin{tabular}{llc}
\hline Genes & Forward primer sequence $\left(\mathbf{5}^{\prime} \rightarrow \mathbf{3}^{\prime}\right)$ & Reverse primer sequence $\left(\mathbf{5}^{\prime} \rightarrow \mathbf{3}^{\prime}\right)$ \\
\hline TNF- $\boldsymbol{\alpha}$ & CACCACGCTCTTCTGTCTACTG & GCTACGGGCTTGTCACTCG \\
$\mathbf{I L} \mathbf{1} \boldsymbol{\beta}$ & AGTTGACGGACCCCAAAAG & AGCTGGATGCTCTCATCAGG \\
$\mathbf{I L - 6}$ & GACAAAGCCAGAGTCATTCAGAG & GTCTTGGTCCTTAGCCACTCC \\
GAPDH & GCCAAGGTCATCCATGACAAC & GTGGATGCAGGGATGATGTTC \\
\hline
\end{tabular}

